\title{
Factors Affecting Parents' Acceptance towards Children with Familial Intellectual Disability (ID)
}

\author{
Elsa Gusrianti ${ }^{1}$, Tri Indah Winarni², Sultana MH Faradz*2 \\ ${ }^{1}$ Magister of Biomedical Science Majoring in Genetic Counseling Program, Faculty of Medicine, Diponegoro \\ University, Semarang, Indonesia \\ ${ }^{2}$ Center for Biomedical Research (CEBIOR), Faculty of Medicine, Diponegoro University, Semarang, Indonesia
}

\section{Article Info}

History:

Received: 20 Nov 2018

Accepted: 28 Nov 2018

Available: 31 Dec 2018

\begin{abstract}
Background: Familial intellectual disability (ID) is a condition where two or more family members are affected ID, which may influence the whole family well-being. Children with intellectual disability often receive negative response from the society, which may trigger different reactions from the parents, such as denial or neglect of their child. Besides, most parents give more attention and provide the best care for their children. Factors that may influence parents' acceptance towards children with familial ID are social support, religious coping, supporting facilities, family income, education, mothers' age, and other significant factors. Indonesia has many different cultures, this research has only been done in Central Java Province, so it only focused on Javanese culture.

Objective: This study was aimed to analyze factors that affect parents' acceptance towards children with familial intellectual disabilities (ID).

Methods: This was an analytic observational study with cross sectional approach. Data were collected using interview with 20 mothers of familial intellectually disabled children including demographic data, pedigree construction, using Parental Rejection Questionnaire (PARQ), Brief Arab Religious Coping Scale (BARCS), Social Support Questionnaire Short Form (SSQSR) and Supporting Facilities Questionnaires. Data was analyzed using multivariate logistic regression.

Results: Parents' acceptance was significantly affect by social support $(\mathrm{p}=0.039)$, while religious coping, supporting facilities, family income, education, and mothers's age did not significantly influence parents' acceptance $(\mathrm{p}>0.05)$.

Conclusion: Social support has influenced parents' acceptance of their familial ID Children
\end{abstract}

Keywords: Familial ID, parents' acceptance, social support, religious coping, Indonesia.

Permalink/ DOI: https://doi.org/10.14710/jbtr.v4i2.3659

\section{INTRODUCTION}

Intellectual Disability (ID) is a disability characterized by significant limitations on intellectual function, adaptive behavior, daily practical skills, which occur before the age of 18 (WHO Regional Office for Europe, 2016). The prevalence of ID in developing countries is $2-3 \%$, although it is estimated and the number is widely varied ${ }^{1,2}$

\footnotetext{
* Corresponding author:

E-mail: sultanafaradz@gmail.com
}

The causes of ID are very complex including various factors, such as biochemistry or metabolic disorders, chromosomal abnormalities, single genes disorders, multifactorial, and environmental factor, thus, that ID's causes can be classified into genetic, multifactorial, and environmental factors. The causes of non-genetic factors of ID are due to alcohol, teratogen agents, infections, perinatal trauma or asphyxia ${ }^{3,4}$.

To date, X-linked ID is the most common genetic cause of ID, and since 1980s, the emerging number of genetic cause associated with the gene located in the $\mathrm{X}$ 
chromosome increased year to year. The most common of the X-Linked ID is Fragile X syndrome (FXS) with the prevalence of 1 in 4000-6000 men and 1 in 700010000 women, and was estimated at $10-12 \%$ of families with X-Linked ID ${ }^{2,5}$. Of those, familial ID occurs in $12 \%$ of total cases and genetic causes were estimated at $25-50 \%$. Parents who have more than 1 child with ID in the family might experience or had severe psychological burden, in addition to the physical and socio-economical burden, responsibility of taking care, and stigma from the community were very hard for them ${ }^{6-8}$.

Children with ID usually get negative responses from the community, causing various parents reactions, such as parents who experiencing with denial stage will exclude the children or did not want to recognize their children, before finally reaching the acceptance stage. ${ }^{9}$ On the other hand, some parents try to give more attention and give the best effort for their children ${ }^{10}$. Parents' acceptance of to the children with ID was affected by several factors namely social support, family income, strong religious coping, education level, marital status, parents' age, and assesiblity of supporting facilities ${ }^{11,12}$. The previous research done by Kandel and Merrick (2007), was carried out in the families with only one affected child, while this study was done in the family who had more than one child with ID (familial ID) in the nuclear family. Understanding of factors that affect the parents'acceptance toward children with familial ID is very important for diseases management and outcome because parent's acceptance will predict the compliance with treatment plans.

\section{MATERIALS AND METHODS \\ Design}

This was cross sectional study included 20 participants with inclusion criteria was parents who had more than one child with ID (familial) from Bina Grahita Social Rehabilitation Center (BBRSBG) Temanggung, and from BBRSBG assisted community, YPAC special school Semarang, Hj. Sumiati special school, and patients who were admitted to Center for Biomedical Research (CEBIOR) Faculty of Medicine, Diponegoro University, Semarang.

\section{Participants and research settings}

The inclusion criteria of study participant were mothers who have more than one child with ID in their family. The total participants in this study were 20 participants consisted of four parents from BBRSBG Temanggung and nine parents from the community supervise by BBRSBG Temanggung, one parents from YPAC Semarang, one parents from $\mathrm{Hj}$. Sumiati special school, five parents from CEBIOR. This research had been approved by Ethics Committee Faculty of Medicine Diponegoro University/dr. Kariadi Hospital. Prior to the interview, the parents were given explanation about purposes, objectives, and procedures of the study, and asked for approval to be included in the study by providing written informed consent. Home visit was done to collect the data. Demographic data including maternal age, family income, parents education, employeement status and pedigree construction were done prior to structured interview questionnaires. Research instruments were Social Support Questionnaire Short Form (SSQRS) created by Sarason $\mathrm{IG}^{13}$, Brief Arab Religious Coping Scale (BARCS) created by Amer $\mathrm{M}^{14}$, supporting facilities were compiled by researcher and validated by three expertise (expert judgmental) and Parental Acceptance-Rejection questionnaire (PARQ) created by Ronald and Nancy Rohner ${ }^{15}$.

\section{Measurement}

Data collection was obtained from structured interviews using PARQ to find out parents' acceptance toward children with familial ID. PARQ consisted of 24 questions with the score range was 1-96, and score categories of $\leq 48$ was rejection and $>48$ was acceptance. SSQSR questionnaire was used to measure participants satisfaction on social support from the community consisted of 6 items with Likert score range of 1-6 using categorical assessment. The score 1 means "very dissatisfied", 2 "fairly dissatisfied, 3 "a little dissatisfied", 4 "a little satisfied", 5 "fairly satisfied", 6 "very satisfied". The calculation of total satisfaction scores for even-numbered was $\max .=36$, the oddnumbered was $\max .=54$, and was divided by 6 per item satisfaction score. The influence of the religious coping was measured by using the BARCS questionnaires that consisted of 15 questions with the score range of $0-45$ and wasc categorized into $\leq 15=$ not good, $>15=$ good. To measure the influence of the supporting facilities, the ten question with the score ranging from $0-40$, and was categorized into $0 \%-25 \%=$ inadequate, $26 \%-50 \%=$ low adequate, $51 \%-75 \%=$ adequate, $76 \%-100 \%=$ very adequate. Family income, education, and mother's age were analyzed by using demographic data.

\section{Data analysis}

Multivariate logistic regression test was applied to analyze the factors affecting parent's acceptance of familial ID.

\section{RESULTS}

Twenty mothers of children with familial ID were recruited after informed-consenting process. Demographic data were collected using semistructured interview including maternal and paternal age, age of participant, formal education, occupation, and family income. Pedigree construction was done for three generation family tree. Parental Rejection Questionnaire (PARQ), Brief Arab Religious Coping Scale (BARCS), Social Support Questionnaire Short Form (SSQSR) and Supporting Facilities Questionnaires were completed using semi-structured interview.

More than a half (55\%) of the maternal ages were 2630 years old, $40 \%$ of the paternal ages were $26-30$ years old, and $40 \%$ of the age participant were $46-55$ years old. The characteristics of participants from the educational status were $50 \%$ did not go to school (no formal education), based on the employment status 
$75 \%$ were housewives, and $65 \%$ earned $<1 \mathrm{M} /$ month. (See Table 1)

Table 1. Demographic data of the participants

\begin{tabular}{|c|c|c|}
\hline Characteristics & $\mathbf{N}$ & $\%$ \\
\hline \multicolumn{3}{|l|}{ Maternal age } \\
\hline $16-20$ & 4 & $20 \%$ \\
\hline $21-25$ & 5 & $25 \%$ \\
\hline 26-30 & 11 & $55 \%$ \\
\hline \multicolumn{3}{|l|}{ Paternal age } \\
\hline $16-20$ & 3 & $15 \%$ \\
\hline $21-25$ & 5 & $25 \%$ \\
\hline $26-30$ & 8 & $40 \%$ \\
\hline $31-35$ & 2 & $10 \%$ \\
\hline $36-40$ & 2 & $10 \%$ \\
\hline \multicolumn{3}{|l|}{ Age participant } \\
\hline $26-35$ & 1 & $5 \%$ \\
\hline $36-45$ & 6 & $30 \%$ \\
\hline $46-55$ & 8 & $40 \%$ \\
\hline $56-65$ & 3 & $15 \%$ \\
\hline$>65$ & 2 & $10 \%$ \\
\hline \multicolumn{3}{|l|}{ Education } \\
\hline Elementary School & 4 & $20 \%$ \\
\hline Junior High School & 3 & $15 \%$ \\
\hline Senior High School & 0 & $0 \%$ \\
\hline Undergraduate & 3 & $15 \%$ \\
\hline Degree & 10 & $50 \%$ \\
\hline \multicolumn{3}{|l|}{ Have no school } \\
\hline \multicolumn{3}{|l|}{ Occupation } \\
\hline House wife & 15 & $75 \%$ \\
\hline Laborer & 1 & $5 \%$ \\
\hline Farmer & 1 & $5 \%$ \\
\hline Private employee & 1 & $5 \%$ \\
\hline Others & 2 & $10 \%$ \\
\hline \multicolumn{3}{|l|}{ Family income (million) } \\
\hline$<1$ & 13 & $65 \%$ \\
\hline $1-2$ & 5 & $25 \%$ \\
\hline$>2$ & 2 & $10 \%$ \\
\hline
\end{tabular}

The result above showed that 11 participants (55\%) from the total subjects 'accepted' their children with familial ID and 9 participants (45\%) from the total subjects 'rejected' their children with familial ID (see figure 1).

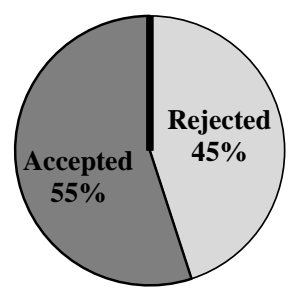

Figure 1. Parents' acceptance towards children with familial intellectual disabilities

Eleven participants who accepted children with familial ID, 2 (10\%) of those were fairly satisfied with their social support and $6(30 \%)$ were a little satisfied with their social support. Nine (45\%) having low adequate supporting facililies. In religious coping, from 11 participants, there were 7 participants were cathegorized good in religious coping. Education background of 11 participants, nine participants were not formally educated. Ten participants had income more 1 million IDR/month. (See Table 2)

The multivariate logistic regression test revealed that social support had significant affect on the parents'acceptance with $p=0.039(<0.05)$. (See Table 3)

\section{DISCUSSION}

To the best of our knowledge, this was the first study conducted in more than one affected ID child in the nuclear family which observed parents' acceptance toward familial ID by analyzing social support, religion

Table 2. The percentages of parents' acceptance toward children with familial ID associated with social support, supporting facilities and religious coping

\begin{tabular}{|c|c|c|c|}
\hline \multirow{2}{*}{\multicolumn{2}{|c|}{ Factors }} & \multicolumn{2}{|c|}{ Acceptance } \\
\hline & & $\begin{array}{l}\text { Rejected } \\
\mathrm{n}=9(\%)\end{array}$ & $\begin{array}{l}\text { Accepted } \\
\mathrm{n}=11(\%)\end{array}$ \\
\hline \multicolumn{4}{|c|}{ Social Support } \\
\hline- & Very Satisfied & $3(15)$ & - \\
\hline- & Fairly Satisfied & $6(30)$ & $2(10)$ \\
\hline- & A little Satisfied & - & - \\
\hline- & A little & - & $6(30)$ \\
\hline & Dissatisfied & & \\
\hline- & Fairly Dissatisfied & - & $3(15)$ \\
\hline & Very Dissatisfied & - & - \\
\hline \multicolumn{4}{|c|}{ Supporting Facilities } \\
\hline- & Very adequate & $4(20)$ & $1(5)$ \\
\hline - & Adequate & $5(25)$ & $1(5)$ \\
\hline- & Low Adequate & - & $9(45)$ \\
\hline- & Inadequate & - & - \\
\hline \multicolumn{4}{|c|}{ Religious coping } \\
\hline- & Good & $9(45)$ & $4(20)$ \\
\hline- & Not Good & - & $7(35)$ \\
\hline \multicolumn{4}{|c|}{ Education Background } \\
\hline- & $\begin{array}{l}\text { Undergraduate } \\
\text { degree }\end{array}$ & $3(15)$ & - \\
\hline - & Senior High School & - & - \\
\hline - & Junior High School & $2(10)$ & $1(5)$ \\
\hline- & Elementary School & $3(15)$ & $1(5)$ \\
\hline- & Have No School & $1(5)$ & $9(45)$ \\
\hline Family & Income (million & & \\
\hline - & $>2$ & $1(5)$ & $1(5)$ \\
\hline- & $1-2$ & $5(25)$ & - \\
\hline- & $<1$ & $3(15)$ & $10(50)$ \\
\hline \multicolumn{4}{|c|}{ Mother Age (years) } \\
\hline- & $26-35$ & $1(5)$ & - \\
\hline- & $36-45$ & $4(20)$ & $2(10)$ \\
\hline- & $46-55$ & $2(10)$ & $6(30)$ \\
\hline - & $56-65$ & $1(5)$ & $2(10)$ \\
\hline- & $>65$ & $1(5)$ & $1(5)$ \\
\hline
\end{tabular}

coping, supporting facilities, family income, educational background of the parents, and mothers' age. The first interesting result of this study showed that the most maternal and paternal age range was 2630 years old; this was not in accordance with the research by Cohen ${ }^{9}$. In previous study, it concluded that the greatest chance of acquiring a child with ID was advance maternal age over 34 years old ${ }^{16,17}$. 
Table 3. Factors affecting parents' acceptance toward children with familial ID

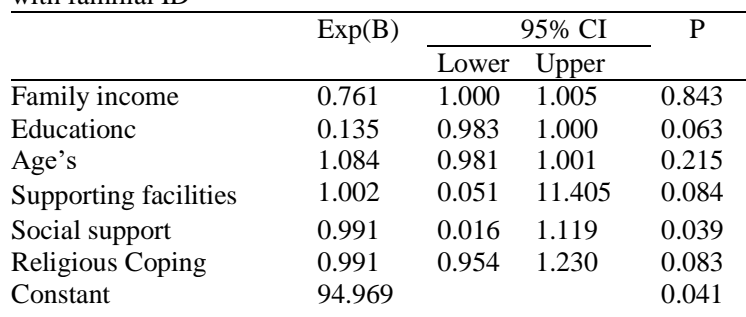

By using PARQ, it can be concluded that there were $55 \%$ of parents accept their children with familial ID. World wide study showed that all individual including children need acceptance as an evident of being loved from parents and other attachment figures. When the need is not met, a specific form of maladaptive behavior was reported, they were more prone to develop behavior problem, and mental health problem ${ }^{15}$. Parental acceptance is assessed in one forms warmth or affection and parental rejection is assessed in three forms, aggressiveness, neglect and reject ${ }^{18}$. Children with ID especially familial ID facing with rejection or unwarmth from parents or family member who is morally responsible to the children. Parental acceptance is very important factor that can affect developmental trajectory in children with ID, although in previous study showed that parent education background and socio-economic class contribute to parental warmth ${ }^{19}$. In this study, social support was the most factor affect to parents' acceptance toward children with familial ID. This was shown by the level of parents' satisfaction to the social support that was provided by people or communities or institutions close to where they lived. The social support referred to the whole society, from the main family, neighboring communities, as well as formal supports such as counselors, medical personnel or government (social workers). The result of this research was in accordance with the previous research which stated that social support was capable in decreasing the negative impacts such as acceptance's status, stress, and improving quality of life $\mathrm{e}^{20-23}$. Social support indicates positive implications for parents' acceptance toward their children.

Religious coping did not significantly affect parents' acceptance towards children with familial ID in this study. This was in line with the study by Lifshitz and Merrick (2003) that showed a positive coping pattern or positive adaptive function parents performance on the individual with ID that tend to changeable and adjustable along with the development of the individual with $\mathrm{ID}^{24,25}$. Meanwhile, the study done in Maryland county, United States showed that religious coping had a big role, which should be applied in daily life as well as the participation in religious activities and support from religious leaders and members of the religious worshipers that were important and significantly affect religious coping and handling challenging situation in rising up their disabled children $^{26,27}$. The spirituality in parents among diabled children across 12 country (European, US, Australia, and Canada) was the instrument to help parents to cope and build resilience against disability, and those associated with the availability of health care facilities and providers who working with the disabilities ${ }^{28}$. Indonesia legally acknowledges six religions: Islam 87.18\%, Catholicism 2.9\%, Protestantism 6.96\%, Buddhism $0.72 \%$, Hinduism $1.69 \%$, and confucianism $0.05 \%$. Indonesia is the largest Muslim population country and having high religious belief in the world, Islam emerged as its dominant influence ${ }^{29}$. Interestingly, instead of positive affect the parent's acceptance, this study showed that religious coping was not contribute significantly. Cultural diversity may also influence to people's viewpoint of people with ID from religious and healthy aspect ${ }^{30}$. In addition, in Indonesia, where the health care facilities and providers associated with the need of disabled people are mostly not available and so the religious coping per se did not significantly affect parent's acceptance.

The supporting facilities in this study mean the availability of health care facilities and provider for the community. Low adequate supporting facility was the most complaint as much as $45 \%$ of participants, especially health care facilities such as the availability of Community Health Centre, integrated health service and hospitals. In this study, supporting facilities did not influence parent's acceptance toward children with familial ID. This result were different from the previous study that showed that the existence of such supporting facilities eased the parents to seek healing for their children with ID and made them easily accept their children with ID. Individual with ID demanded attention to fulfill the needs of the individual's health services with familial $\mathrm{ID}^{28,31}$. In Indonesia, where the average of the society is in the low to middle social classes, the understandings of the needs of the respective therapeutic, the facilities provided was very poor. Supporting facilities are assessed as a tertiary need where it is not a significant need that becomes the focus of parent's attention having children with familial ID, the emergence of feelings of rejection and depression toward the presence of children with familial ID more due to the presence of conditions the birth of a child that does not fit the parents' initial expectations, and so that parents effort to keep families in a harmonious and in balanced state requires considerable time and support not just from external factors such supporting facilities but also internal factors such as quality of life and parents coping strategy, however, this study did not acess those factors $11,32,33$.

Family income is one of internal factor that may influence parent's acceptance, where children with familial ID have specific problems which have more costs unlike usual health problems, education, and parenting ${ }^{34,35}$. In this study, 10 out of 11 parent who accept children with familial ID having low family income/month (minimum wage in Central Java was two million IDR/month), although family income did not statistically contribute to parent's acceptance. This study also not conchordance with previous studies that showed the acceptance towards children with ID was affected by several factors, one of them was the family income $^{36,37}$, but the problems that experienced by 
families who have children with familial ID is exceeding the burden of income itself, parents more focused on the efforts to reduce the level of stress experienced $^{38}$. Parents education (all participants were mother) did not significantly affect the parents' acceptance toward children with familial ID. In the previous research, it was described that it was due to the education that related to the ability to analyze and think rationally, so that in terms of acceptance due to a high sense of concern was not caused by education. Education was more focuses on individual coping mechanisms rather than on the acceptance towards children with familial ID. The presence of the individual with ID within a family must have an impact on the whole family, and it will stimulate an understandings to the family that it must be accepted, the feeling of receiving tends to be perceived by fate $^{39,40}$. Mother's age ranging from 26 to 65 years old, it was categorized into mature age, however mothers' age did not significantly affect the parents' acceptance toward children with familial ID. Previous study suggested that the age of the individual did not necessarily indicate a person's maturity, the maturity of a person was determined more by the number of experiences encountered problem. In addition, a study indicated the different levels of stress susceptibility between father and mother in parenting of children with familial ID was more contribute to the acceptance level ${ }^{39}$, beside the length of disease period which may in accordance with parent's age was one of the factors which influence parents' acceptance ${ }^{10}$.

\section{LIMITATION OF STUDY}

The limitation of this research was that this research has only been done in Central Java Province, so it only focused on one kind of culture. In Indonesia, different provinces have different cultures and probably also different on how to accept children with familial ID. Furthermore, study with larger participants with various cultural backgrounds is needed because it will represent the picture of parent's acceptance in Indonesia.

\section{CONCLUSIONS}

Social support is an important factor that affect parents acceptance towards children with familial ID conducted in Indonesia.

\section{ACKNOWLEDGMENTS}

This work would not be held without the financial support by Beasiswa Unggulan BPKLN fellowship from Indonesia Ministry of Education and Culture. We thank to BBRSBG Temanggung and also appreciation to parents, CEBIOR Faculty of Medicine, Diponegoro University and other special school that help this study conducted. We thank the family who participated in this study. We all address our appreciation to all the school committee who were involved for their help in this study. We would also like to show our gratitude to our parents who provided support that greatly assisted the researcher.

\section{REFERENCES}

1. Strømme P. ARX and other single genes in $\mathrm{X}-$ linked mental retardation : revisiting a populationbased study. J Pediatr Neurol. 2005;3:121-2.

2. Pouya AR, Abedini SS, Mansoorian N. Fragile X syndrome screening of families with consanguineous and non-consanguineous parents in the iranian population. Eur $\mathrm{J}$ Med Genet. 2009;52(4):170-3.

3. Karnebeek CDM Van, Jansweijer MCE, Leenders AGE, Offringa M, Hennekam RCM. Diagnostic investigations in individuals with mental retardation : a systematic literature review of their usefulness. Eur J Hum Genet. 2005;13:6-25.

4. de Ligt J, Willemsen $\mathrm{MH}$, van Bon BWM, Kleefstra T, Yntema HG, Kroes T, et al. Diagnostic Exome Sequencing in Persons with Severe Intellectual Disability. N Engl J Med [Internet]. 2012;367(20):1921-9. Available from: http://www.nejm.org/doi/abs/10.1056/NEJMoa12 06524

5. Tariverdian G, Vogel F. Some problems in the genetics of X-linked mental retardation. Cytogenet Cell Genet. 2001;91(2000):278-84.

6. Lundvall M, Rajaei S, Erlandson A, Kyllerman M. Aetiology of severe mental retardation and further genetic analysis by high-resolution microarray in a population-based series of 6- to 17-year-old children. Epidemiol Sev Ment Retard. 2012;(101):85-91.

7. Neeely-Barnes SL, Dia DA. Families of children with disabilities: a review of literature and recommendations for interventions. $\mathbf{J}$ Early Intensive Behav Interv. 2012;5(3):93-107.

8. Plant KM, Sanders MR. Predictors of care-giver stress in families of preschool-aged children with developmental disabilities. J Intellect Disabil Res. 2007;51(2):109-24.

9. Cohen PN. Parental age and cognitive disability among children in the united states. Parent Age Cogn Disabil. 2014;1:102-10.

10. Seltzer MM, Floyd FJ, Song J, Greenberg JS, Hong J. Developmental disabilities : impacts of lifelong parenting. Natl Institutes Heal. 2012;116(6):479-99.

11. Kandel I, Merrick J. The child with a disability: parental acceptance, management and coping. Sci World J. 2007;(7):1799-809.

12. Taanila A, Syrjälä L, Kokkonen J, Järvelin M. Coping of parents with physically and/or intellectually disabled children. Child Care, Heal Dev. 2002;28(1):73-86.

13. Irwin G. Sarason, Barbara R. Sarason ENS\& GRP. SocialSupportQuestionnaireShort2.pdf. 1987. p. 497-510.

14. Amer MM, Hovey JD, Fox CM, Rezcallah A. Initial development of the brief Arab Religious Coping Scale (BARCS). J Muslim Ment Health. 2008;3(1):69-88.

15. Ronald P. Rohner, Khaleque, Abdul DEC. Parental Acceptance-Rejection: Theory, Methods, Cross-Cultural Evidence, and Implications. Am Anthro- pological Assoc. 2005;33(3):299-334. 
16. Zhen H, Lawson AB, Mcdermott S, Lamichhane AP, Aelion M. A spatial analysis of mental retardation of unknown cause and maternal residence during pregnancy. Geospat Heal. 2015;2(2):173-82.

17. Zheng X, Chen R, Li N, Du W, Pei L, Zhang J, et al. Socioeconomic status and children with intellectual disability in china. J Intellect Disabil Res. 2012;56(2):212-20.

18. Rohner RP, Khaleque A, Cournoyer DE. Introduction to parental acceptnce-rejecton theory, methods, evidence, and implications. Overv Parent Accept Theory. 2012;1-31.

19. Khan EA, Riaz MA. Demographic Differences on Parental Acceptance Rejection and Personality among Children with Intellectual Disabilities. J Appl Environ Biol Sci. 2014;4(7S):364-72.

20. Sajjad S. Stress faced by mothers of children with intellectual disability and its impact on their family life. Dep Spec Educ. 2015;1-55.

21. Hassall R, Rose J, Mcdonald J. Parenting stress in mothers of children with an intellectual disability : the effects of parental cognitions in relation to child characteristics and family support. J Intellect Disabil Res. 2005;49(6):405-18.

22. Long ACJ. Parenting stress and social support in families with children with fragile $\mathrm{x}$ syindrome: a comparison of mothers and fathers. Diss Dr Philos. 2009;1-86.

23. Bodla G, Saima W, Ammara T. Social support and psychological wellbeing among parents of intellectually challenged. Int $\mathrm{J}$ Rehabil Sci. 2012;1(2):29-35.

24. Lifshitz H, Merrick J. Ageing and intellectual disability in Israel : a study to compare community residence with living at home. Heal Soc Care Community. 2003;11(4):364-71.

25. Lifshitz H, Merrick J. Aging among persons with intellectual disability in Israel in relation to type of residence, age , and etiology. Res Dev Disabil. 2004;25:193-205.

26. O'Hanlon EE. Religion and disability: the experiences of families of children with special needs. J Relig Disabil Heal. 2013;17(1):37-41.

27. Poston DJ, Turnbull AP. Role of spirituality and religion in family quality of life for families of children with disabilities. Educ Train Dev Disabil. 2004;39(2):95-108.
28. Pandya SP. Spirituality and Parents of Children With Disability: Views of Practitioners. J Disabil Relig. 2017;21(1):64-83.

29. Badan Pusat Statistik Indonesia. Data Penduduk menurut Wilayah dan Agama yang Dianut - Data Sensus Penduduk 2010. Available at https://sp2010.bps.go.id/index.php/site/tabel?tid= 321\&wid=0. Accessed on January 8, 2018.

30. Crotty G, Doody O. Transcultural care and individuals with an intellectual disability. J Intellect Disabil. 2016;20(4):386-96.

31. Ervin DA, Hennen B, Merrick J, Morad M. Healthcare for persons with intellectual and developmental disability in the community. Front Public Heal. 2014;2(1):1-8.

32. MB O, CP H. Depression in mothers and fathers of children with intellectual disability. J Intellect Disabil Res. 2001;45(6):535-43.

33. Ganjiwale D, Ganjiwale J, Sharma B, Mishra B. Quality of life and coping strategies of caregivers of children with physical and mental disabilities. J Fam Med Prim Care. 2016;5(2):343.

34. Araújo CAC de, Paz-Lourido B, Gelabert SV. Types of support to families of children with disabilities and their influence on family quality of life. Article. 2016;21(10):3121-30.

35. Cuskelly MA. Parents of adults with an intellectual disability. Aust Inst Fam Stud. 2006;(74):20-5.

36. Olsson MB, Hwang CP. Socioeconomic and psychological variables as risk and protective factors for parental well-being in families of children with intellectual disabilities. J Intellect Disabil Res. 2008;52(12):1102-13.

37. Taggart L, Taylor D, Mccrum-gardner E. Individual, life events, family and socioeconomic factors associated with young people with intellectual disability and with and without behavioural / emotional. J Intellect Disabil. 2010;14(4):267-89.

38. Heiman T. Parents of Children With Disabilities : Resilience, Coping, and Future Expectations 1. J Dev Phys Disabil. 2002;14(2):159-71.

39. Boström PK, Broberg M, Hwang P. Parents ' descriptions and experiences of young children recently diagnosed with intellectual disability. J Compil. 2009;1-8.

40. Aydin A, Yamac A. The relations between the acceptance and child- rearing attitudes of parents of children with mental. Eurasian J Educ Res. 2014;(54):79-98. 